Article

\title{
Effects of a Detailed Vegetation Database on Simulated Meteorological Fields, Biogenic VOC Emissions, and Ambient Pollutant Concentrations over Japan
}

\author{
Satoru Chatani ${ }^{1, *(1)}$, Motonori Okumura ${ }^{2}$, Hikari Shimadera ${ }^{3}$, Kazuyo Yamaji ${ }^{4}$, \\ Kyo Kitayama ${ }^{1}$ and Sou N. Matsunaga ${ }^{5}$ \\ 1 National Institute for Environmental Studies, Tsukuba, Ibaraki 305-8506, Japan; kitayama.kyo@nies.go.jp \\ 2 Research Institute of Environment, Agriculture and Fisheries, Osaka Prefecture, Habikino, Osaka 583-0862, \\ Japan; OkumuraM@mbox.kannousuiken-osaka.or.jp \\ 3 Graduate School of Engineering, Osaka University, Suita, Osaka 565-0871, Japan; \\ shimadera@see.eng.osaka-u.ac.jp \\ 4 Graduate School of Maritime Sciences, Kobe University, Kobe, Hyogo 658-0022, Japan; \\ kazuyo@maritime.kobe-u.ac.jp \\ 5 Taikisha Ltd., Aikawa, Aikou, Kanagawa 243-0308, Japan; so-matsunaga@taikisha.co.jp \\ * Correspondence: chatani.satoru@nies.go.jp; Tel.: +81-29-850-2740
}

Received: 30 March 2018; Accepted: 7 May 2018; Published: 9 May 2018

\begin{abstract}
Regional air quality simulations provide powerful tools for clarifying mechanisms of heavy air pollution and for considering effective strategies for better air quality. This study introduces a new vegetation database for Japan, which could provide inputs for regional meteorological modeling, and estimating emissions of biogenic volatile organic compounds (BVOCs), both of which are essential components of simulations. It includes newly developed emission factors (EFs) of BVOCs for major vegetation types in Japan, based on existing literature. The new database contributes to improved modeling of meteorological fields due to its updated representation of larger urban areas. Using the new vegetation and EF database, lower isoprene and monoterpene, and higher sesquiterpene emissions are estimated for Japan than those derived from previously available default datasets. These slightly reduce the overestimation of ozone concentrations obtained by a regional chemical transport model, whereas their effects on underestimated secondary organic aerosol (SOA) concentrations are marginal. Further work is necessary, not only on BVOC emissions but also the other simulation components, to further improve the modeling of ozone and SOA concentrations in Japan.
\end{abstract}

Keywords: biogenic volatile organic compounds; regional air quality simulation; land use; vegetation; emission inventory

\section{Introduction}

Biogenic volatile organic compounds (BVOCs) emitted from vegetation have critical roles in photochemical reactions, producing harmful ambient pollutants including ozone and secondary organic aerosols (SOA) (e.g., [1]). However, there is limited understanding of the types and amounts of BVOCs emitted from vegetation. The Japanese Government has recognized that establishing a reliable BVOC emission inventory is vital for developing effective strategies to suppress ambient ozone and $\mathrm{PM}_{2.5}$ concentrations, which still exceed Environmental Quality Standards (EQSs) in Japan [2].

The Model of Emissions of Gases and Aerosols from Nature (MEGAN) [3-5] has been used to estimate BVOC emissions worldwide. Default input database is available to estimate emissions for any 
region. However, this database does not necessarily reflect the detailed characteristics of vegetation in each country. Kim et al. [6] created a database of plant functional types (PFTs) based on Korea-specific vegetation database. They found noticeable disparities in simulated ozone concentrations when estimating BVOC emissions using their database versus the default database. Kota et al. [7] showed that the default database over-predicted biogenic isoprene in northern downtown Houston, which resulted in higher SOA concentrations being predicted by their simulations. Sakulyanontvittaya et al. [8] created a new database of land use and land cover (LULC) and PFTs based on satellite data for central Alberta, Canada, which outperformed the default database when estimating BVOC emissions. These studies suggest that the use of default database does not always provide the best estimate of BVOC emissions; consequently, it may be necessary to develop a localized database that more accurately represent vegetation in target areas. In addition, Schurgers et al. [9] and Wang et al. [10] indicated the importance of individually representing BVOC emissions from dominant tree species, instead of aggregating them into PFTs.

Chatani et al. [11] accordingly developed a gridded database of emission factors (EFs) and vegetation to estimate BVOC emissions throughout Japan, using MEGAN version 2.04 [3,5]. Dominant tree species in Japan were individually represented. They found that using this database to estimate BVOC emissions led to significant differences in concentrations of ozone and SOA in air quality simulations. However, their targets were limited to isoprene, monoterpenes, and sesquiterpenes emitted from trees, and they did not include other VOCs and vegetation types, which needed to be treated separately. The EFs were derived from limited measurements, whereas more data have since become available. Therefore, the present study updates the existing EF and vegetation database by utilizing the latest literatures and datasets available for Japan, to seamlessly estimate all forms of biogenic VOC emissions from all types of vegetation in Japan, with a newer version 2.1 of MEGAN [4].

BVOC emissions are used as one of the emission inputs to air quality simulations. A typical air quality simulation framework includes a regional meteorological model to simulate meteorological fields, and this model requires land use information. Therefore, updating the vegetation database may influence not only BVOC emissions, but also the meteorological fields simulated by a regional meteorological model if utilized as a land use input. In the case of the Weather Research and Forecasting (WRF) model, the default land use database of United States Geological Survey (USGS) was prepared. However, Schicker et al. [12] obtained more realistic meteorological fields in Austrian regions when using a land use database generated in the Coordination of Information on the Environment (CORINE) program. Cheng et al. [13] also showed better agreement with observed wind speed in Taiwan in their simulations when using a land use database based on Système Probatoire d'Observation de la Terre (SPOT) satellite imagery. They indicated that more accurate meteorological fields could be obtained by regional meteorological models using more realistic land use database. The present study investigates the effects of employing an updated vegetation and EF database for simulated meteorological fields, estimated BVOC emissions, and simulated ambient ozone and SOA concentrations in Japan.

Details of the air quality simulations and the updated database are described in Section 2. The influences of the updated database on meteorological fields, BVOC emissions, and ambient concentrations of ozone and SOA are described in Section 3. Implications and remaining challenges are discussed in Section 4. The study findings are summarized in Section 5.

\section{Methodology}

\subsection{Air Quality Simulation Framework}

This study applied the regional air quality simulation framework, following Japan's Study for Reference Air Quality Modeling (J-STREAM) [14]. Only the components relevant to this study are described in this section, while other details were introduced by Chatani et al. [14].

Meteorological fields were simulated by the Weather Research and Forecasting (WRF)-Advanced Research WRF (ARW) version 3.7.1 [15]. USGS land use data, which have 24 classifications, were used 
as an input to the base simulation. Ambient pollutant concentrations were simulated by the Community Multiscale Air Quality (CMAQ) modeling system version 5.1 [16] using the SAPRC07 chemical mechanism [17] and aero6 aerosol module. While isoprene and $\alpha$-pinene are treated separately, other monoterpenes and sesquiterpenes are lumped into surrogate groups: TERP and SESQ, respectively. As for SESQ, reactions with $\mathrm{OH}, \mathrm{O}_{3}$, and $\mathrm{NO}_{3}$ are included. Semi-volatile compounds are produced in these reactions. Their partitioning to the aerosol phase is represented by Carlton et al. [18], and the parameters used for sesquiterpenes are based on Griffin et al. [19]. BVOC emissions estimated by MEGAN version 2.1 [4], using the default database in the base simulation, were utilized. The default gridded database contains EFs only for isoprene, $\alpha$-pinene, $\beta$-pinene, 3 -carene, limonene, 2 -methyl-3-buten-2-ol (232-MBO), myrcene, $\mathrm{t}-\beta$-ocimene, and sabinene. Emissions of other VOCs were estimated from the gridded database of PFTs and the default EFs specified for each PFT [4]. Because the default gridded database contains PFTs only for North America, the land use input to WRF was utilized after allocating the 24 USGS land use classifications to the 16 PFTs used in MEGAN version 2.1. The targets consist of four nested domains named as $\mathrm{d} 01, \mathrm{~d} 02, \mathrm{~d} 03$, and $\mathrm{d} 04$ that cover most of East, South, and Southeast Asia (d01), most of Japan (d02), the city cluster in western Japan (d03), and the Tokyo metropolitan area (d04). The mesh sizes of d01, d02, d03, and d04 are $45 \times 45 \mathrm{~km}$, $15 \times 15 \mathrm{~km}, 5 \times 5 \mathrm{~km}$, and $5 \times 5 \mathrm{~km}$, respectively. This paper mainly discusses the results for d04; and as a supplement, those of d03, to show a situation at a similar scale to d04, and in d02 to show background influences on d03 and d04. These domains are shown in Figure 1.

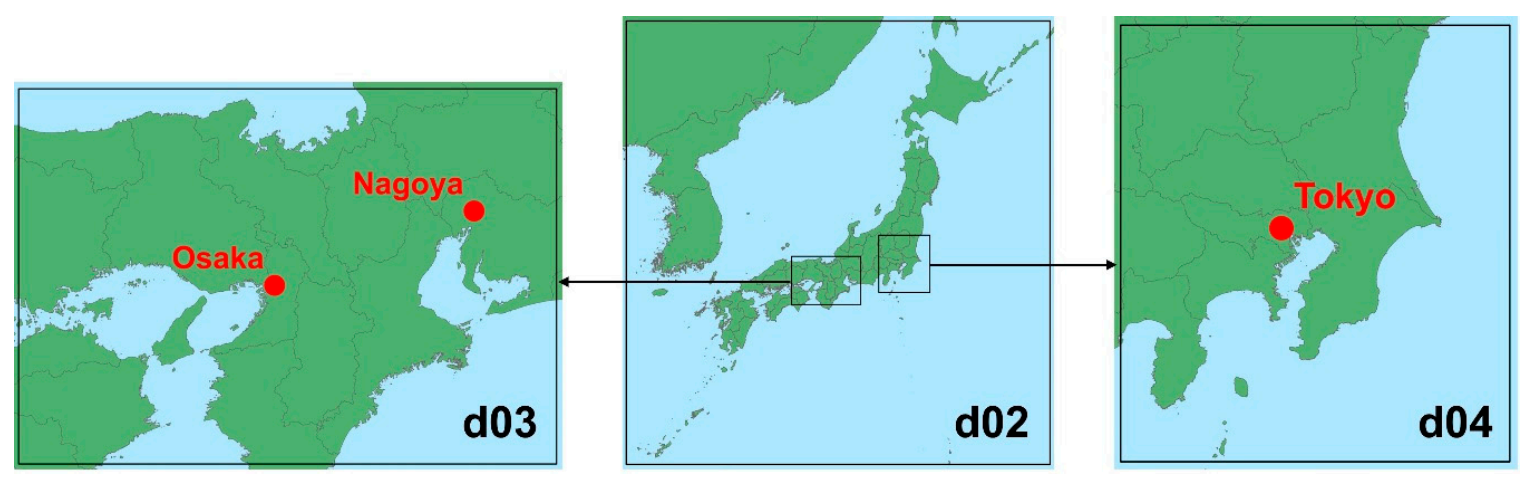

Figure 1. Target domains d02, d03, and d04, which are mainly discussed in this paper.

\subsection{Vegetation Database}

A new vegetation database for Japan was created from geographic information system (GIS) data based on the 6th and 7th Vegetation Surveys released by the Biodiversity Center of Japan, Ministry of Environment. Most of Japan is covered by 1:25,000 vegetation maps, and remaining regions are supplemented by 1:50,000 equivalents. These consist of polygons representing 58 vegetation groups, each with several subgroups. The attributes of the corresponding 24 USGS land use classifications and 16 PFTs were added to all the polygons based on vegetation definitions for each group and subgroup. Input datasets of land use classifications to WRF and PFTs to MEGAN were prepared by discretizing the polygons into the meshes in the target domains using GIS software.

\subsection{EF Database}

In addition to the default EFs specified for 16 PFTs in MEGAN version 2.1 [4], individual EFs were derived for major vegetation types in Japan by averaging the values reported in the existing literature. These comprised EFs of isoprene emitted from Quercus serrata [20-22], Quercus dentata [22], Quercus crispula [20,22,23], Fagus crenata [20], Quercus acutissima [20,22], Quercus glauca [20,22], Quercus myrsinifolia [20,22], Quercus variabilis [22], Quercus acuta [22], Quercus salicina [22], and Quercus sessilifolia [22]; monoterpenes emitted from Cryptomeria japonica [20,24-28], Chamaecyparis 
obtusa $[20,27,29,30]$, and Pinus densiflora [20,31]; and sesquiterpenes emitted from Cryptomeria japonica [24-27] and Pinus densiflora [32], as shown in Figure 2. Also shown are the EFs of isoprene emitted from broadleaf deciduous or evergreen temperate trees, and those of monoterpenes and sesquiterpenes emitted from needleleaf evergreen temperate trees, specified in the default database [4]. Their average values and standard deviations are shown in Table S1 in the Supplementary Materials. They indicate uncertainties in EFs are still high even if all the available data are gathered.

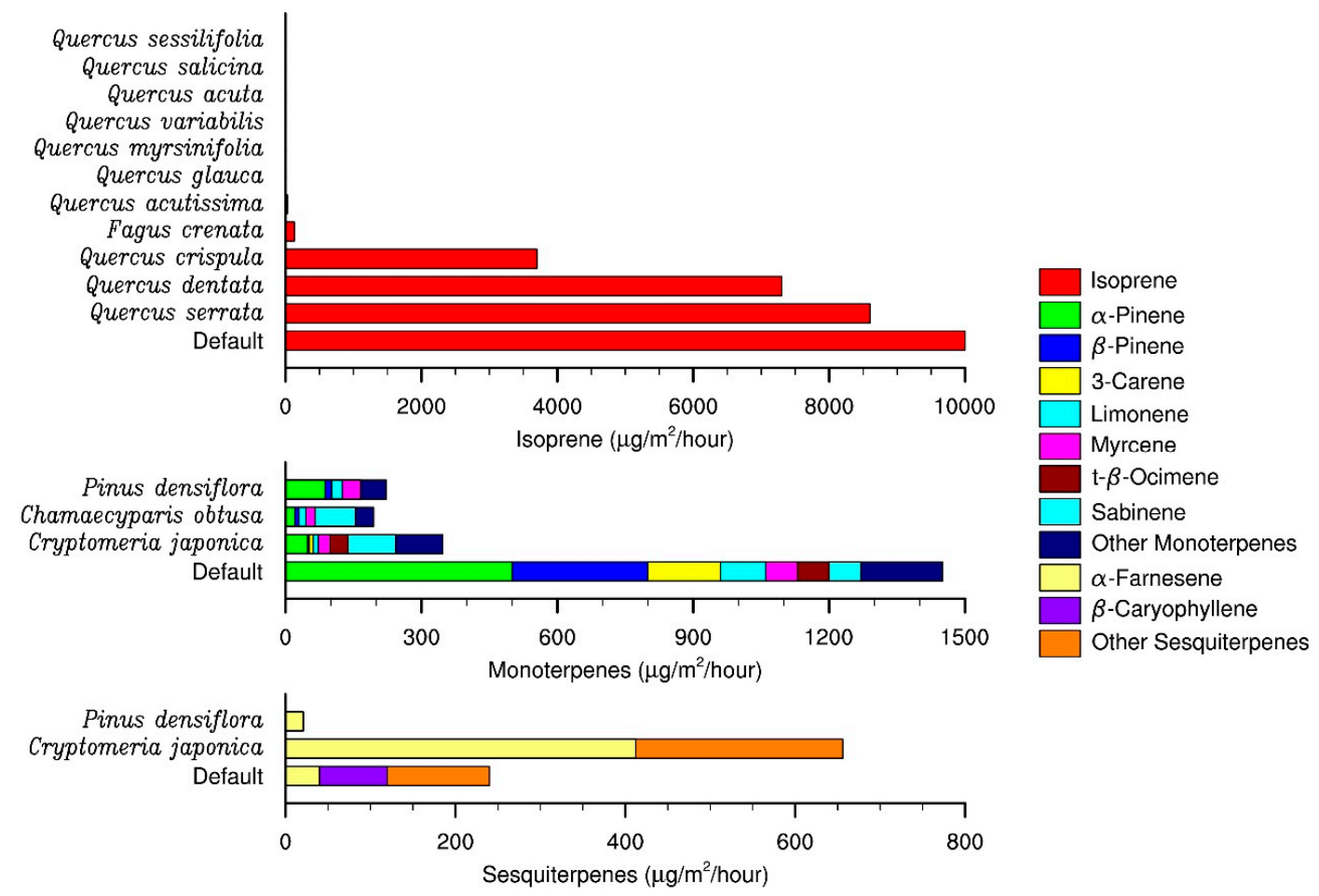

Figure 2. Default and newly developed EFs of isoprene, monoterpenes, and sesquiterpenes for major vegetation types.

All the isoprene EFs, which were individually specified for each type of broadleaf deciduous or evergreen temperate tree shown in Figure 2, are lower than those specified in the default database. Specifically, isoprene emitted from some trees is zero or almost negligible. Guenther et al. [4] mentioned the importance of distinguishing emitters and non-emitters of isoprene, which was realized in the new database. The monoterpene EFs for the temperate evergreen needleleaf tree species Cryptomeria japonica, Chamaecyparis obtuse, and Pinus densiflora are also much lower than the default EFs, except for sabinene. On the other hand, the EFs of $\alpha$-Farnesene and other sesquiterpenes for Cryptomeria japonica are much higher than the default EFs. The EFs defined in the default database were used for the remaining VOCs and vegetation types.

It should be noted that Chatani et al. [11] specified monthly EFs because large variations existed in the EFs measured in different seasons even after they were corrected to the standard condition at which photosynthetic photon flux density (PPFD) and temperature are $1000 \mu \mathrm{mol} \mathrm{m}{ }^{-2} \mathrm{~s}^{-1}$ and $30{ }^{\circ} \mathrm{C}$, respectively. There are studies investigating factors causing seasonal variations of BVOC emissions in addition to solar radiation and temperature. For example, Wei et al. [33] indicated that leaf phenology is a crucial variable causing seasonal variations. However, to date, it is difficult to attribute one of factors to the measured large variations due to lack of detailed information. Therefore, this study treated the variations as uncertainties in each measurement, and all the measured values corrected to the standard condition were simply averaged to obtain annual mean EFs. Seasonal variations in BVOC emissions are represented by various default correction factors embedded in MEGAN version 2.1. 


\subsection{Observation Data for Validation}

Meteorological data from two monitoring networks were used to evaluate model performance on meteorological fields. One dataset was obtained from the Weather Office network. Hourly temperature, relative humidity, and wind speed were compared with simulated values. The network has 31 and 28 offices located within d03 and d04 respectively. The second dataset was obtained by the Automated Meteorological Data Acquisition System (AMeDAS). Hourly temperature and wind speed were compared with simulated values, with 261 and 185 stations located within d03 and d04 respectively.

Ambient ozone concentrations observed at the 341 and 333 ambient air pollution monitoring stations (APMSs), located in d03 and d04 respectively, were used to evaluate model performance on ozone concentrations. Eight-hour maximum concentrations (MDA8O3) calculated from observed hourly concentrations for each station and each day were compared with corresponding simulated values. Organic carbon (OC) concentrations observed during the monitoring campaign for $\mathrm{PM}_{2.5}$ components conducted from 24 July to 6 August 2013 were used to evaluate model performance on concentrations of OC, including SOA formed from BVOC emissions. Daily OC concentrations observed at 33 and 25 stations located in d03 and d04 respectively were compared with corresponding simulated values.

Mean bias (MB), root mean squared error (RMSE), and correlation coefficient (R) were calculated from observed and simulated values for statistical evaluation of the model performance. MB and RMSE were calculated by Equations (1) and (2) respectively.

$$
\begin{aligned}
\mathrm{MB} & =\frac{1}{N} \sum_{i=1}^{N}\left(M_{i}-O_{i}\right) \\
\mathrm{RSME} & =\sqrt{\frac{1}{N} \sum_{i=1}^{N}\left(M_{i}-O_{i}\right)^{2}}
\end{aligned}
$$

Here, $N$ is the number of data, $M_{i}$ is $i$-th simulated value, and $O_{i}$ is $i$-th observed value.

\subsection{Sensitivity Simulation Cases}

Sensitivity simulation cases were conducted to evaluate the influences of the new database on meteorological fields, biogenic VOC emissions, and ozone and SOA concentrations. Two simulation cases shown in Table 1 were conducted to evaluate the influences on meteorological fields. The cases named as BASE and NEW-LU used the default USGS versus the new vegetation database as land use inputs. Differences in the simulated meteorological fields between them correspond to the influences of the new database. Three simulation cases shown in Table 2 were conducted to evaluate the influences on estimated BVOC emissions and simulated ozone and SOA concentrations. The case named as BASE used the default database, whereas the cases named as NEW-VEG and NEW-VEGEF used the PFTs of the new vegetation database. In addition, the NEW-VEGEF case replaced the default EFs, which were used in the BASE and NEW-VEG cases with the new EFs developed in this study. Differences in simulated ozone and SOA concentrations among the three cases correspond to the influences of PFTs and EFs of the new database. All three cases used the same meteorological fields obtained in the NEW-LU case. Simulations were conducted for days from 12 July to 10 August 2013, but the results for the first ten days were discarded as a spin-up period, and those from 22 July to 10 August 2013 are discussed as the target period.

Table 1. Sensitivity simulation cases for meteorological fields and database used in each case.

\begin{tabular}{cc}
\hline Case Name & Land Use \\
\hline BASE & USGS \\
NEW-LU & This study \\
\hline
\end{tabular}


Table 2. Sensitivity simulation cases for BVOC emissions and ambient concentrations and database used in each case.

\begin{tabular}{cccc}
\hline Case Name & Meteorology & PFT & EF \\
\hline BASE & NEW-LU & Default & Default \\
NEW-VEG & NEW-LU & This study & Default \\
NEW-VEGEF & NEW-LU & This study & This study \\
\hline
\end{tabular}

\section{Results}

\subsection{Model Performance on Meteorology}

Figure 3 shows the horizontal distributions of mean temperature at $2 \mathrm{~m}$ height, relative humidity at $2 \mathrm{~m}$ height, and planetary boundary layer (PBL) height simulated in the BASE and NEW-LU cases during the target period in d04. Differences between the two cases are also shown. Corresponding horizontal distributions in d02 and d03 are shown in Figures S1 and S2 respectively. While the differences between the two cases are relatively small in central Tokyo, higher temperature, higher PBL height, and lower relative humidity are evident in the surrounding areas and at scattered points in the NEW-LU case. Their locations correspond to urban areas, as shown in Figure 4. Whereas the land use input employed in the BASE case limits urban areas to central Tokyo, the fractions of urban areas are much larger in major surrounding cities in the land use input used in the NEW-LU case. It appears that higher fractions of urban areas in the NEW-LU case resulted in simulations of higher temperature, higher PBL height, and lower relative humidity.
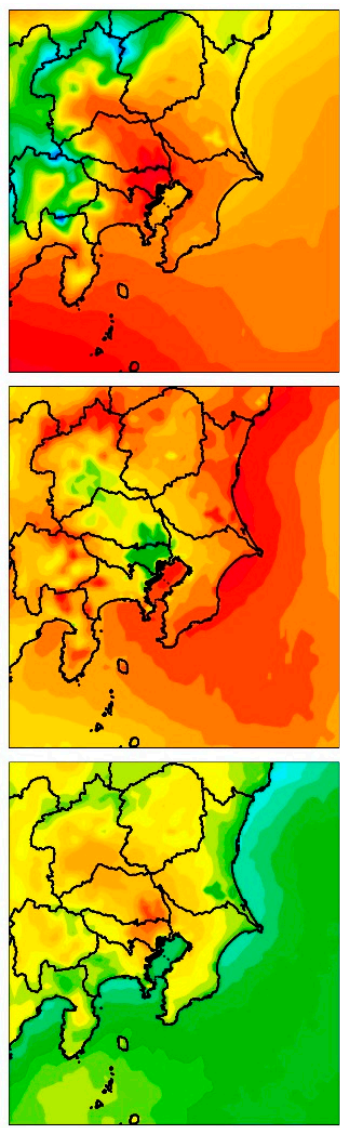

BASE
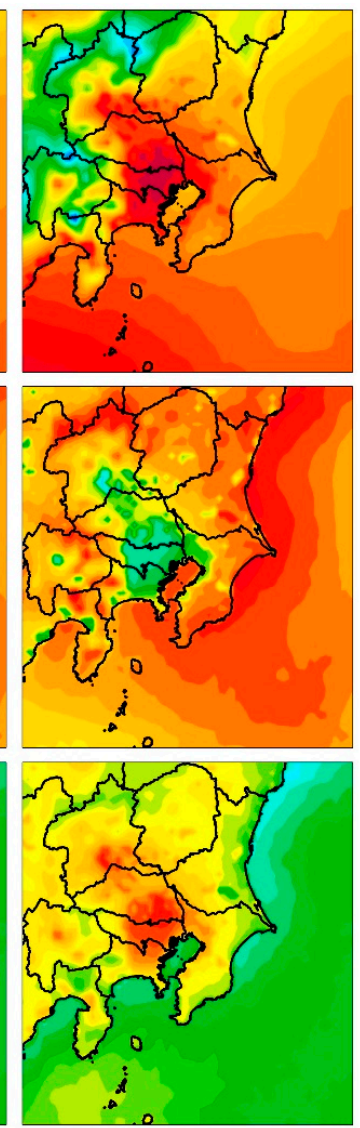

NEW-LU

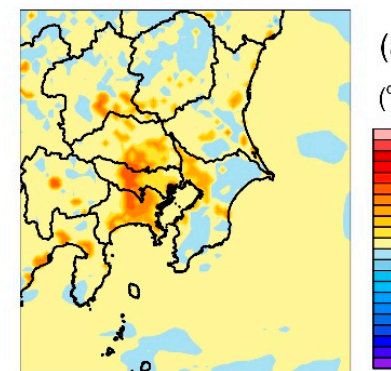

(a) Temperature

$\left({ }^{\circ} \mathrm{C}\right)$
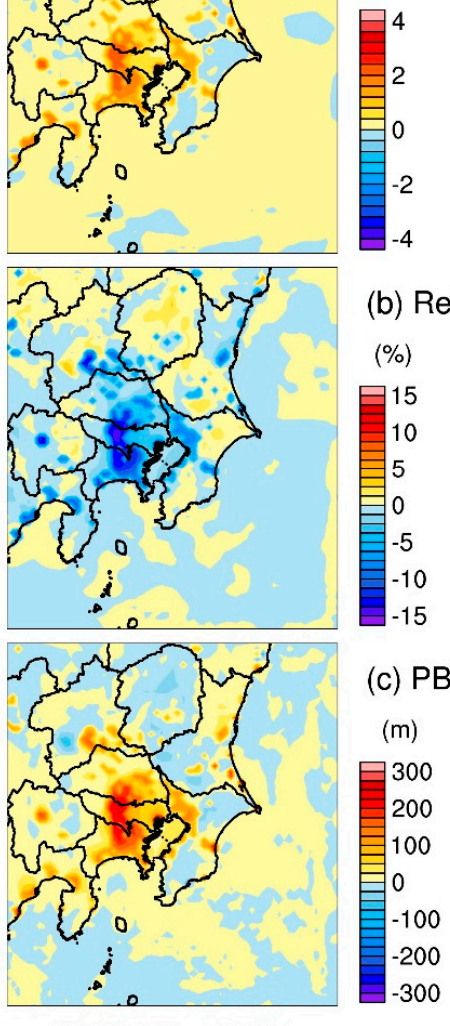

NEW-LU - BASE

Figure 3. Horizontal distributions showing (a) mean temperature at $2 \mathrm{~m}$ height; (b) relative humidity at $2 \mathrm{~m}$ height; and (c) PBL height simulated in BASE and NEW-LU cases during the target period in d04. 


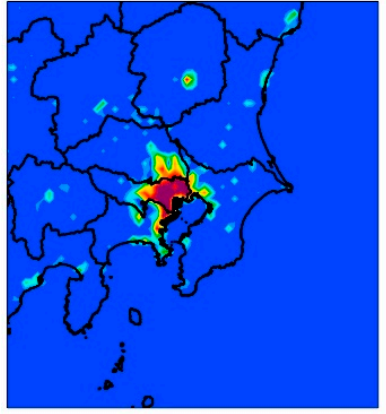

BASE

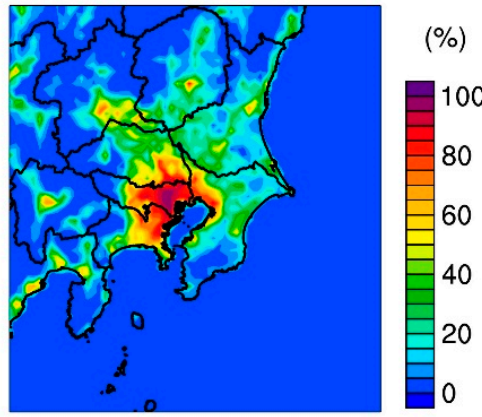

NEW-LU

Figure 4. Urban land use percentage, as input to the BASE and NEW-LU cases in d04.

Table 3 shows statistical evaluation of the model performance for temperature at $2 \mathrm{~m}$ height, relative humidity at $2 \mathrm{~m}$ height, and wind speed at $10 \mathrm{~m}$ height during the target period in d03 and d04. In the BASE case, the MBs of temperature are negative, while those of relative humidity and wind speed are positive, indicating that temperatures were underestimated while relative humidity and wind speed were overestimated. Their magnitudes and RMSEs are smaller in the NEW-LU case. $R$ is mostly better in the NEW-LU case. It is evident that the new vegetation database used as the land use input to the NEW-LU case contributed to better model performance on temperature, relative humidity, and wind speed.

Table 3. Statistical analysis of model performance on temperature at $2 \mathrm{~m}$ height, relative humidity at $2 \mathrm{~m}$ height, and wind speed at $10 \mathrm{~m}$ height during the target period in $\mathrm{d} 03$ and $\mathrm{d} 04$.

\begin{tabular}{|c|c|c|c|c|c|c|}
\hline Parameter & Domain & Network & Case & MB & RMSE & $\mathbf{R}$ \\
\hline \multirow{8}{*}{ Temperature $\left({ }^{\circ} \mathrm{C}\right)$} & \multirow{4}{*}{$\mathrm{d} 03$} & \multirow{2}{*}{ Office } & BASE & -0.93 & 2.2 & 0.82 \\
\hline & & & NEW-LU & -0.047 & 2.1 & 0.81 \\
\hline & & \multirow{2}{*}{ AMeDAS } & BASE & -0.96 & 2.2 & 0.86 \\
\hline & & & NEW-LU & -0.46 & 2.1 & 0.85 \\
\hline & \multirow{4}{*}{$\mathrm{d} 04$} & \multirow{2}{*}{ Office } & BASE & -0.54 & 2.9 & 0.84 \\
\hline & & & NEW-LU & 0.40 & 2.5 & 0.88 \\
\hline & & \multirow{2}{*}{ AMeDAS } & BASE & -0.86 & 2.4 & 0.85 \\
\hline & & & NEW-LU & -0.39 & 2.3 & 0.86 \\
\hline \multirow{4}{*}{ Relative humidity (\%) } & \multirow{2}{*}{ d03 } & \multirow{2}{*}{ Office } & BASE & 2.8 & 11 & 0.72 \\
\hline & & & NEW-LU & -2.6 & 11 & 0.70 \\
\hline & \multirow{2}{*}{$\mathrm{d} 04$} & \multirow{2}{*}{ Office } & BASE & 3.4 & 10 & 0.70 \\
\hline & & & NEW-LU & -1.9 & 10 & 0.72 \\
\hline \multirow{8}{*}{ Wind speed (m/s) } & \multirow{4}{*}{$\mathrm{d} 03$} & \multirow{2}{*}{ Office } & BASE & 0.50 & 1.6 & 0.52 \\
\hline & & & NEW-LU & 0.42 & 1.4 & 0.55 \\
\hline & & \multirow{2}{*}{ AMeDAS } & BASE & 1.2 & 2.0 & 0.42 \\
\hline & & & NEW-LU & 1.0 & 1.8 & 0.45 \\
\hline & \multirow{4}{*}{$\mathrm{d} 04$} & \multirow{2}{*}{ Office } & BASE & 0.51 & 1.6 & 0.51 \\
\hline & & & NEW-LU & 0.43 & 1.5 & 0.54 \\
\hline & & \multirow{2}{*}{ AMeDAS } & BASE & 0.85 & 1.7 & 0.46 \\
\hline & & & NEW-LU & 0.73 & 1.5 & 0.50 \\
\hline
\end{tabular}

\subsection{Estimates of BVOC Emissions}

Figure 5 shows horizontal distributions of mean emission rates of isoprene, monoterpenes, and sesquiterpenes estimated in the BASE, NEW-VEG, and NEW-VEGEF cases during the target 
period in d04. Corresponding horizontal distributions in d02 and d03 are shown in Figures S3 and S4 respectively, in the Supplementary Materials. Estimated emissions are much lower in central Tokyo, but surrounding areas have higher isoprene emissions in the BASE case. In contrast, areas with lower isoprene, monoterpene, and sesquiterpene emissions in the NEW-VEG and NEW-VEGEF cases expand northwestward from central Tokyo into the wider metropolitan Tokyo urban area, as shown in Figure 4. Higher isoprene emissions are seen in the surrounding mountainous areas. Similar features are seen in and around Osaka and Nagoya in d03, as shown in Figure S4. Isoprene and monoterpene emissions in the NEW-VEGEF case are lower than those in the NEW-VEG case throughout the domains, because all the new isoprene and monoterpene EFs are lower than the default EFs as shown in Figure 2. On the other hand, sesquiterpene emissions in the NEW-VEGEF case are higher than those in the NEW-VEG case where Cryptomeria japonica is dominant, as the revised sesquiterpene EFs are higher.
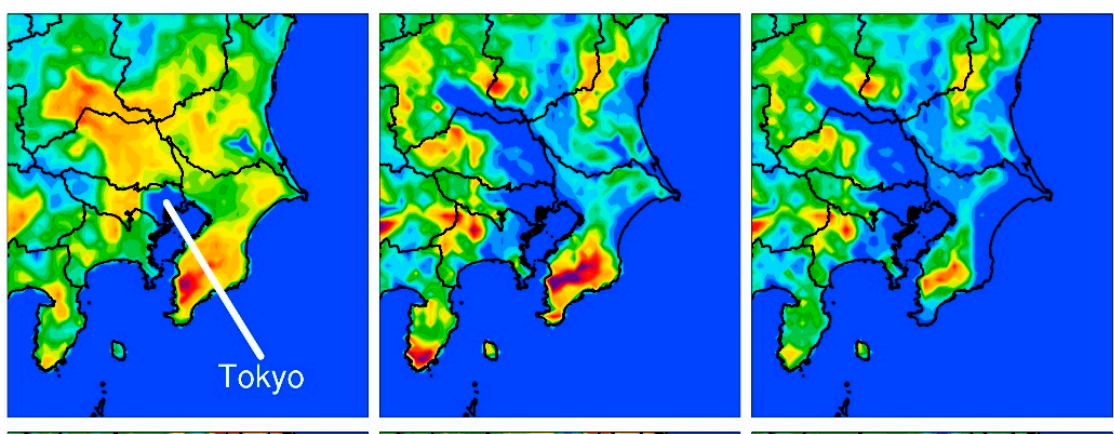

(a) Isoprene
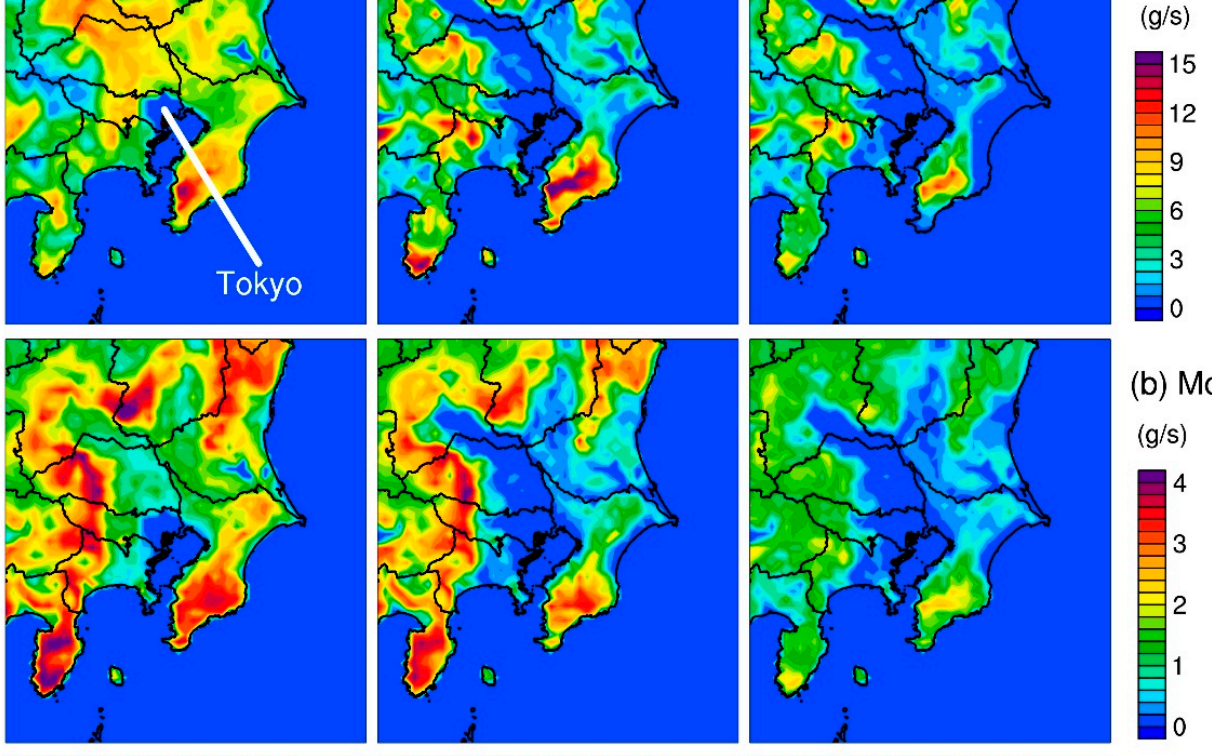

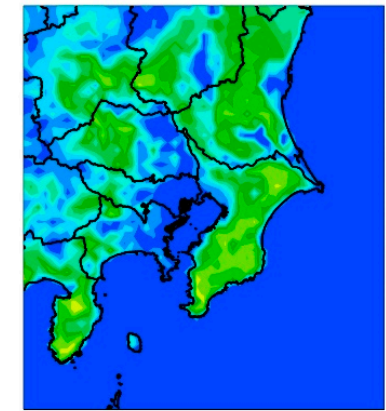

BASE

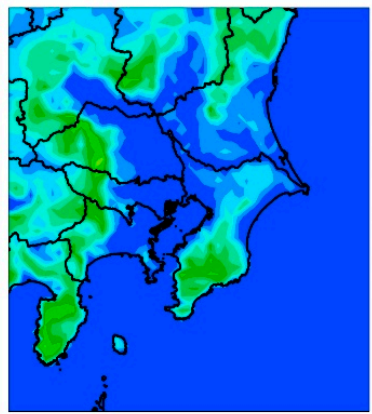

NEW-VEG

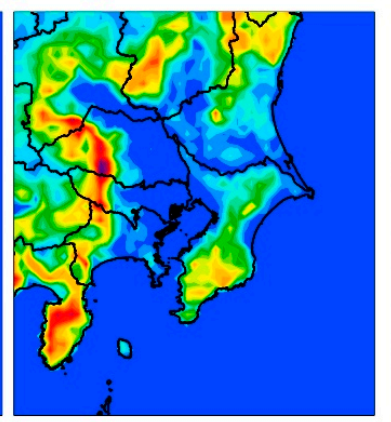

NEW-VEGEF

Figure 5. Horizontal distributions showing mean emission rates of (a) isoprene; (b) monoterpenes, and (c) sesquiterpenes estimated in BASE, NEW-VEG, and NEW-VEGEF cases during the target period in $\mathrm{d} 04$.

Such features are also visible in the total mean emission rates of isoprene, monoterpenes, and sesquiterpenes estimated in the BASE, NEW-VEG, and NEW-VEGEF cases during the target period aggregated in d04, as shown in Figure 6. Corresponding results for d02 and d03 are shown in Figures S5 and S6 respectively, in the Supplementary Materials. The differences observed among the three cases are consistent throughout all of the domains. The mean emission rates of isoprene, monoterpenes, and sesquiterpenes estimated in the NEW-VEG case are lower than those in the BASE case, because 
urban areas (containing less vegetation cover) account for a larger proportion of the new vegetation database used in the NEW-VEG case. This is particularly evident in d04, where the new vegetation database shows much less vegetation in Tokyo and surrounding areas. The mean emission rates are reduced further in the NEW-VEGEF case due to the lower EFs, with the exception of sabinene, $\alpha$-farnesene, and other sesquiterpenes, to which higher EFs were defined for Cryptomeria japonica.

(a) Isoprene

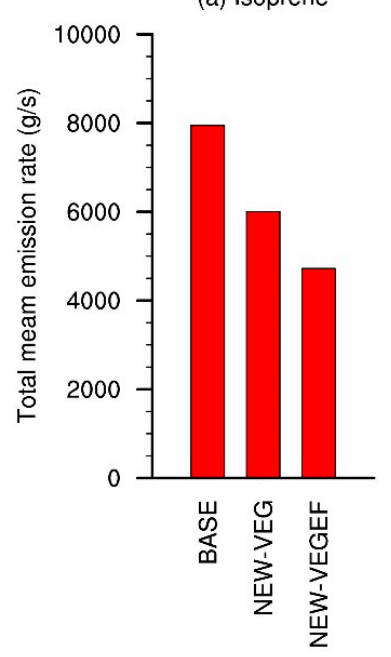

(b) Monoterpenes

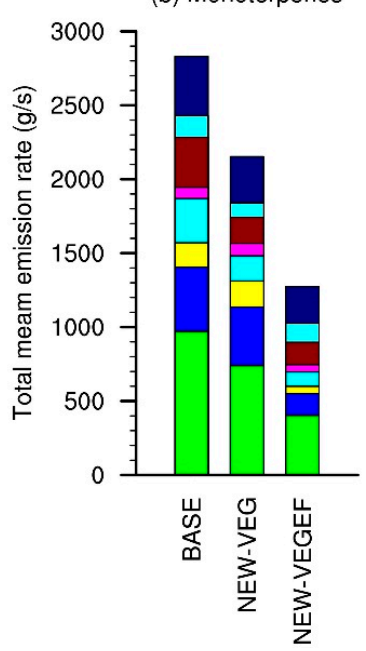

(c) Sesquiterpenes

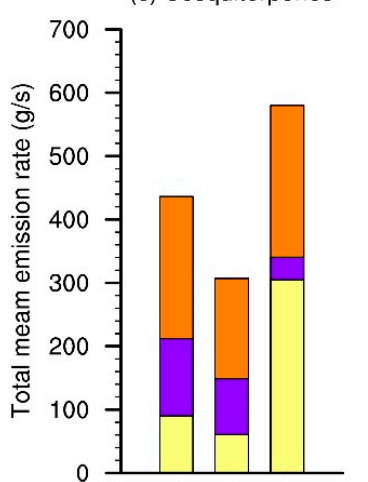

岕 岕

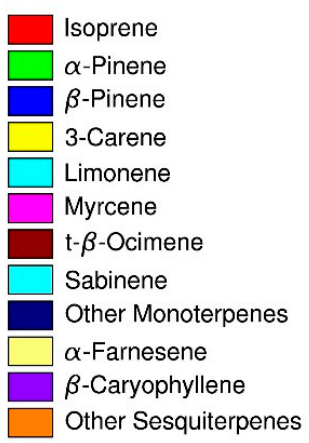

Other Sesquiterpenes

Figure 6. Total mean emission rates of (a) isoprene; (b) monoterpenes; and (c) sesquiterpenes estimated in the BASE, NEW-VEG, and NEW-VEGEF cases during the target period, aggregated in d04.

\subsection{Model Performance on Ambient Concentrations}

Figure 7 shows horizontal distributions of mean surface MDA8O3 simulated in the BASE and NEW-VEGEF cases during the target period in d04. Differences between the two cases are also shown. Corresponding horizontal distributions in d02 and d03 are shown in Figures S7 and S8 respectively, in the Supplementary Materials. Most of Japan shows high concentrations, spreading from the continent, as shown in d02. Concentrations are lower at the center of urban areas, due to titration by $\mathrm{NO}_{X}$ emissions, but are higher in surrounding downwind areas. The BVOC emissions estimated in the NEW-VEGEF case resulted in lower surface MDA8O3 concentrations throughout Japan. The impacts are particularly evident in northern and northwestern downwind regions of the Tokyo metropolitan area, where much lower BVOC emissions were estimated in the NEW-VEGEF case, as shown in Figure 5.

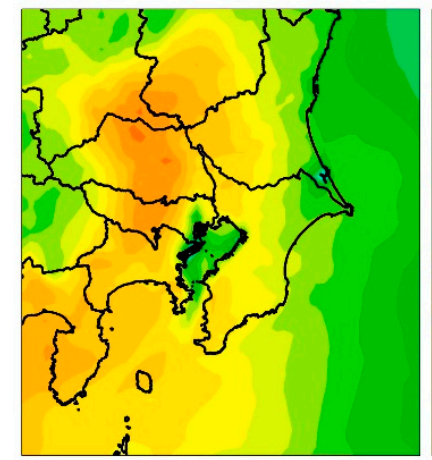

BASE

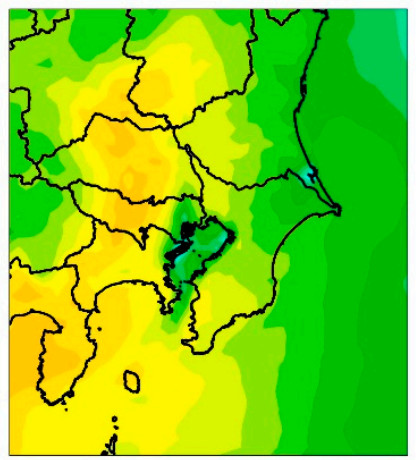

NEW-VEGEF
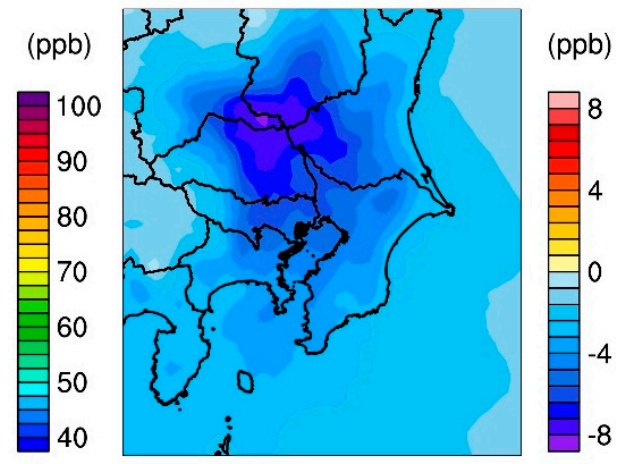

NEW-VEGEF - BASE

Figure 7. Horizontal distributions of mean surface MDA8O3 simulated in the BASE and NEW-VEGEF cases during the target period in d04. Differences between the two cases are also shown. 
Figure 8 compares time series of observed and simulated daily surface MDA8O3 in the BASE, NEW-VEG, and NEW-VEGEF cases during the target period in $\mathrm{d} 03$ and d04. Each point represents the values averaged at all the stations located within the domains. Daily variations are similar between the observed and simulated values, whereas the absolute values of MDA8O3 are overestimated in both domains. Although the new vegetation and EF database achieves closer agreement between simulated and observed values, their discrepancies are much larger than those among the individual BASE, NEW-VEG, and NEW-VEGEF simulations.

(a) $\mathrm{d} 03$

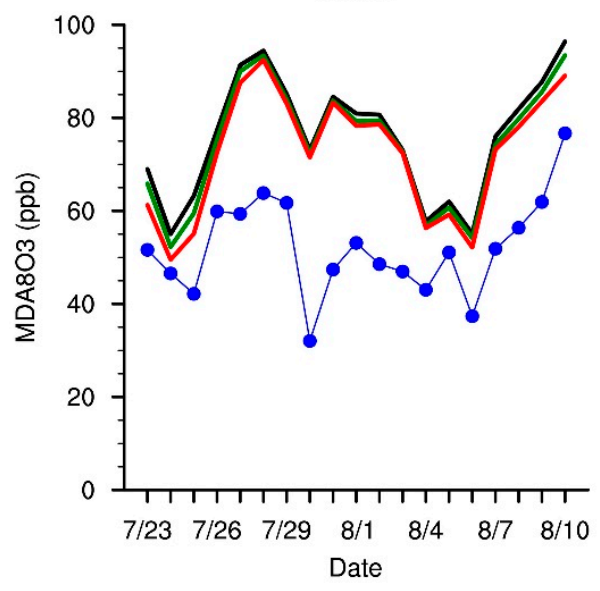

(b) d04

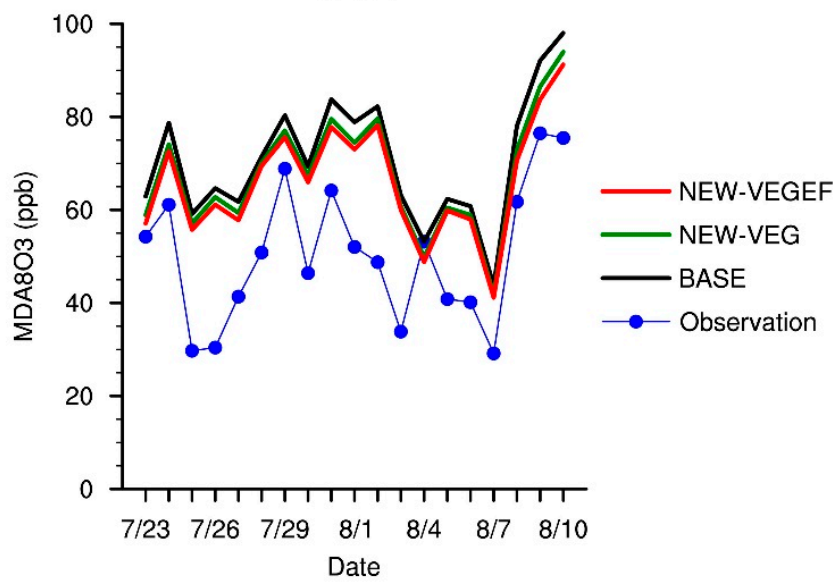

Figure 8. Time series comparisons of observed and simulated daily surface MDA8O3 in the BASE, NEW-VEG, and NEW-VEGEF cases during the target period in (a) d03 and (b) d04.

Table 4 shows statistical analysis of the model performance for daily surface MDA8O3 during the target period in $\mathrm{d} 03$ and $\mathrm{d} 04$. In the BASE case, surface MDA8O3 values in d03 and d04 were overestimated by $23 \mathrm{ppb}$ and $20 \mathrm{ppb}$ respectively. MB and RMSE were lower in the NEW-VEG and NEW-VEGEF cases, whereas $R$ was slightly worse. The new vegetation and EF database resulted in slightly better model performance for surface MDA8O3, but more work is necessary to further minimize the deviations between observed and simulated values.

Table 4. Statistical analysis of model performance for daily surface MDA8O3 during the target period in $\mathrm{d} 03$ and $\mathrm{d} 04$.

\begin{tabular}{ccccc}
\hline Domain & Case & MB (ppb) & RMSE (ppb) & $\mathbf{R}$ \\
\hline \multirow{4}{*}{ d03 } & BASE & 23 & 28 & 0.77 \\
& NEW-VEG & 22 & 26 & 0.76 \\
& NEW-VEGEF & 20 & 25 & 0.75 \\
\hline \multirow{3}{*}{ d04 } & BASE & 20 & 25 & 0.87 \\
& NEW-VEG & 17 & 23 & 0.86 \\
& NEW-VEGEF & 15 & 22 & 0.86 \\
\hline
\end{tabular}

Figure 9 shows horizontal distributions of mean surface SOA concentrations simulated in the BASE and NEW-VEGEF cases from 22 July to 10 August 2013 in d04. Differences between the two cases are also shown. Corresponding horizontal distributions in d02 and d03 are shown in Figures S9 and S10 respectively, in the Supplementary Materials. The horizontal distributions of SOA concentrations in $\mathrm{d} 02$ are similar to those of surface ozone; most of Japan is encompassed by high concentrations, spreading from the continent. The BVOC emissions estimated in the NEW-VEGEF case resulted in higher SOA concentrations in some north-central parts of Japan. Figure S11 in the Supplementary Materials separately shows the horizontal distributions of the differences in mean surface SOA concentrations 
originating from isoprene, monoterpenes, and sesquiterpenes simulated in the BASE and NEW-VEGEF cases from 22 July to 10 August 2013 in d02, d03, and d04. SOA concentrations originating from sesquiterpenes are higher in most parts of Japan in the NEW-VEGEF cases due to the higher EF for Cryptomeria japonica. On the other hand, the NEW-VEGEF case has lower isoprene emissions, and so SOA concentrations originating from isoprene are lower, particularly in southern parts of Japan. Therefore, only limited areas show increased SOA concentrations in the NEW-VEGEF case.

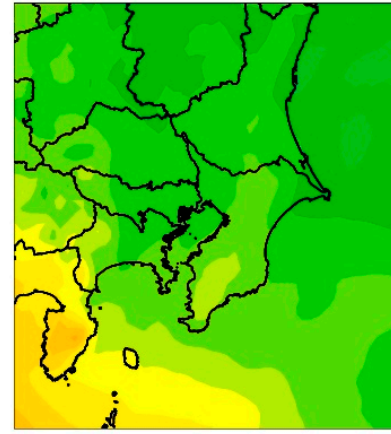

BASE

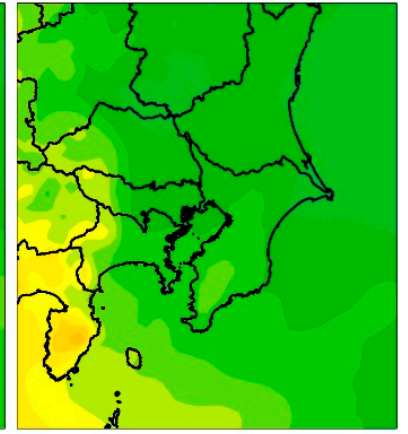

NEW-VEGEF

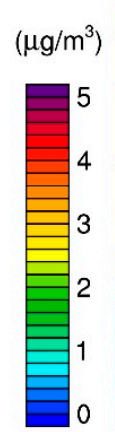

. NEW-VEGEF - BASE

Figure 9. Horizontal distributions of mean surface SOA concentrations simulated in the BASE and NEW-VEGEF cases during the target period in d04. Differences between the two cases are also shown.

Figure 10 compares time series of observed and simulated daily surface OC concentrations in the BASE, NEW-VEG, and NEW-VEGEF cases during the monitoring campaign in d03 and d04. Each point represents the values averaged at all the stations located within the domains. Although the daily variations show some similarities between the observed and simulated values, the absolute values are underestimated in all the cases. Differences among the BASE, NEW-VEG, and NEW-VEGEF cases are evident only on a limited number of days, and the new vegetation and EF database does not necessarily contribute to better model performance on OC concentrations.

(a) d03

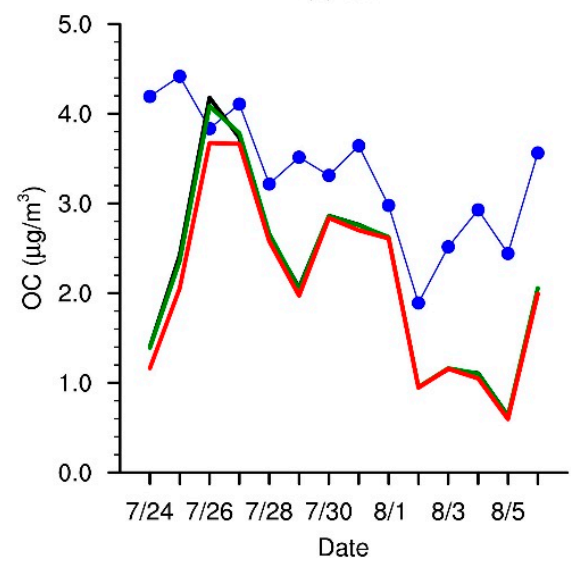

(b) d04

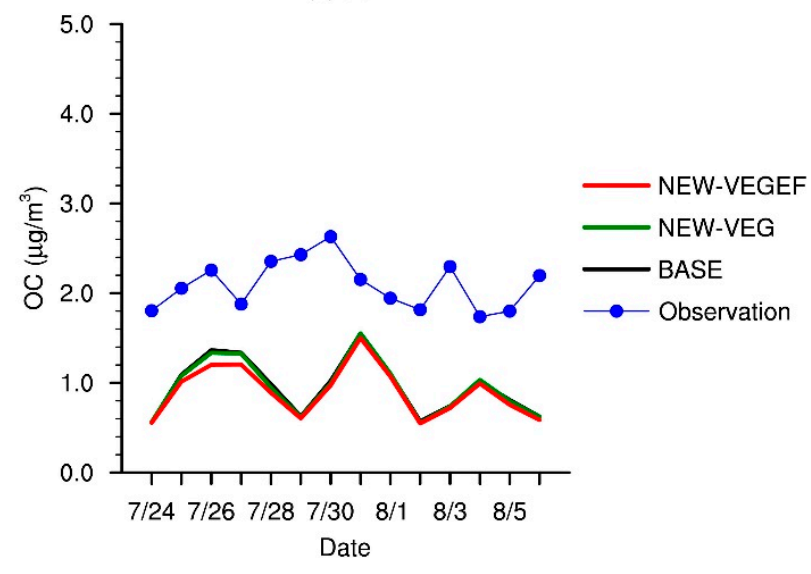

Figure 10. Time series comparisons of observed and simulated daily OC concentrations in the BASE, NEW-VEG, and NEW-VEGEF cases during the monitoring campaign in (a) d03 and (b) d04.

Table 5 shows statistical analysis of the model performance for daily surface OC concentrations during the monitoring campaign in $\mathrm{d} 03$ and d04. In the BASE case, surface OC concentrations in d03 and d04 were underestimated by $1.1 \mu \mathrm{g} / \mathrm{m}^{3}$ and $1.2 \mu \mathrm{g} / \mathrm{m}^{3}$, respectively. Differences among the BASE, NEW-VEG, and NEW-VEGEF cases are marginal. The new vegetation and EF database did not result in statistically better model performance on OC concentrations. 
Table 5. Statistical analysis of model performance for daily surface OC concentrations during the monitoring campaign in $\mathrm{d} 03$ and $\mathrm{d} 04$.

\begin{tabular}{ccccc}
\hline Domain & Case & MB $\left(\mu \mathrm{g} / \mathbf{m}^{3}\right)$ & RMSE $\left(\mu \mathrm{g} / \mathbf{m}^{3}\right)$ & $\mathbf{R}$ \\
\hline \multirow{4}{*}{ d03 } & BASE & -1.1 & 1.8 & 0.41 \\
& NEW-VEG & -1.1 & 1.8 & 0.41 \\
& NEW-VEGEF & -1.2 & 1.9 & 0.38 \\
\hline \multirow{3}{*}{ d04 } & BASE & -1.2 & 1.4 & 0.27 \\
& NEW-VEG & -1.2 & 1.5 & 0.29 \\
& NEW-VEGEF & -1.2 & 1.5 & 0.29 \\
\hline
\end{tabular}

\section{Discussion}

A better model performance on meteorological fields obtained in the NEW-LU case indicates the importance of more realistic land use inputs in regional meteorological simulations. In particular, the representation of urban areas could greatly affect simulated temperature, relative humidity, and PBL height. In the case of Austria, Schicker et al. [12] found many more urban grid cells in their updated land-use database compared with the default USGS data, resulting in higher and better-simulated temperature when using their updated input. Cheng et al. [13] also indicated that most regions of Taiwan were not classified as urban areas in the USGS data, contrary to the actual situation, thereby under-predicting temperature in urban areas. The present findings are consistent with these examples. In most regions, it appears that urban areas tend to be underrepresented in the USGS dataset compared with the currently observed situation. On the other hand, WRF users easily rely on USGS because it was provided as a default land use input until its recent version 3.7.1. In order to achieve better model performance for meteorological fields in regional simulations, it is necessary to check whether land use inputs accurately represent urban areas.

Most previous air quality simulation studies (e.g., $[34,35])$ overestimated ozone concentrations over Japan. One possible explanation is that BVOC emissions were estimated using less accurate representations of vegetation types and their BVOC EFs. It is critical to ensure more accurate representation of BVOC emissions within air quality simulations, as this could alter regimes of ambient ozone formation and the relative importance of controls on anthropogenic $\mathrm{NO}_{X}$ and $\mathrm{VOC}$ emissions [36,37]. However, better representation of BVOC emissions in Japan is not a single solution for eliminating overestimation of its ambient ozone concentrations, as these are greatly influenced by ozone transport from the continent, particularly during summer 2013 [38]. Therefore, it is necessary to find other ways to reduce simulated ambient ozone concentrations at the larger regional scale.

The contributions of the new vegetation and EF database to better model performance on SOA concentrations were seen only in limited areas. In addition, the magnitude of the increase in simulated SOA concentrations was not significant. These findings differ from those of Chatani et al. [11], who reported significant increase in simulated SOA concentrations during summer over areas where Cryptomeria japonica is dominant. One possible explanation is that they used different EFs for each month, reflecting seasonal variations in measured EFs. In contrast, the present study treated these variations as biases, and used average EFs in all measurements. If their monthly EFs represent actual situations, it is necessary to clarify additional mechanisms that might alter BVOC emissions, such as leaf phenology [33], stresses [39], and drought [40-42], other than those considered in MEGAN, such as dependence of emissions on solar radiation and temperature.

Figure S12 in the Supplementary Materials shows the horizontal distributions of the mean surface SOA concentrations originating from isoprene, monoterpenes, and sesquiterpenes simulated in the NEW-VEGEF cases from 22 July to 10 August 2013 in d02, d03, and d04. SOA originating from isoprene is dominant in all the domains. Isoprene chemistry updated in CMAQ version 5.1 results in higher SOA concentrations [43]. Influences of lower isoprene emissions may be more pronounced in this study than Chatani et al. [11], in which isoprene chemistry had not been updated. Sesquiterpenes 
contribute to more SOA formation than monoterpenes. However, sesquiterpene chemistry is quite uncertain. van Eijck et al. [44] indicated that oxidation products of $\beta$-caryophyllene, which is one of major sesquiterpenes, obtained in the chamber experiments were underestimated by Master Chemistry Mechanism (MCM) [45], which is much more detailed chemical mechanism than SAPRC07. The underestimation of SOA may be caused by uncertainties in isoprene and sesquiterpene chemistry.

Moreover, an underestimation of OC concentrations is not necessarily caused by BVOC. Primary emitted OC and SOA formed from anthropogenic VOC emissions are included in ambient OC. It is essential to distinguish their influences. Matsui et al. [46] and Morino et al. [47] implied that SOA originating from anthropogenic VOCs was more important than BVOCs. Morino et al. [48] showed that better model performance on OC concentrations over Japan during summer was achieved by the Volatile Basis Set (VBS) approach. VBS can deal with direct emissions of semi-volatile and intermediate-volatility organic compounds, the oxidation of these compounds, and aging. These studies implied that not only biogenic, but also anthropogenic primary OC and VOCs-including semi-volatile components-significantly influence simulated OC concentrations. Detailed measurements of ambient organic compounds, including markers, could help identify their sources [49].

Further research is necessary to improve model performance regarding overestimated ozone and underestimated OC concentrations in Japan. These tasks should be tackled in J-STREAM through inter-model comparisons [14].

\section{Conclusions}

A new vegetation and EF database was developed to more accurately represent the situation in Japan. The database showed larger coverage of urban land use, and resulted in better model performance on meteorological fields. EFs for major vegetation types in Japan were determined based on the available literature. These were mostly lower than those prepared in the default MEGAN input database, except for sesquiterpenes emitted from Cryptomeria japonica, which is the most popular tree species in Japan. Emissions estimated using the new database were lower for isoprene and monoterpenes, and higher for sesquiterpenes. These results contributed to slightly better model performance on simulated ozone concentrations, whereas their effects on simulated SOA concentrations were marginal.

Although we believe the new vegetation and EF database could improve the modeling of meteorological fields and ambient pollutant concentrations in Japan, the present approach has some limitations. The new EF database includes vegetation types based on dominant areal coverage but not their respective emissions. Consequently, important BVOC emitters may be omitted from the new database. Even if the new database could resolve detailed vegetation parameters, it is not possible to represent further small-scale vegetation such as trees along streets and in urban parks, which may be important in urban areas with high $\mathrm{NO}_{X}$ emissions [50]. Uncertainties in the compiled EFs are still high. Moreover, vegetation is changing over time due to various factors including climate change. Such a dynamic change in vegetation should affect BVOC emissions [51]. It is necessary to gather more information and data to more precisely represent vegetation and resulting BVOC emissions in order to further improve model performance on meteorological fields and ambient pollutant concentrations.

Supplementary Materials: The following are available online at http://www.mdpi.com/2073-4433/9/5/179/s1, Figure S1: Horizontal distributions showing mean temperature at $2 \mathrm{~m}$ height, relative humidity at $2 \mathrm{~m}$ height, and PBL height simulated in BASE and NEW-LU cases during the target period in d02, Figure S2: Horizontal distributions showing mean temperature at $2 \mathrm{~m}$ height, relative humidity at $2 \mathrm{~m}$ height, and PBL height simulated in BASE and NEW-LU cases during the target period in d03, Figure S3: Horizontal distributions showing mean emission rates of isoprene, monoterpenes, and sesquiterpenes estimated in BASE, NEW-VEG, and NEW-VEGEF cases during the target period in d02, Figure S4: Horizontal distributions showing mean emission rates of isoprene, monoterpenes, and sesquiterpenes estimated in BASE, NEW-VEG, and NEW-VEGEF cases during the target period in d03, Figure S5: Total mean emission rates of isoprene, monoterpenes, and sesquiterpenes estimated in the BASE, NEW-VEG, and NEW-VEGEF cases during the target period, aggregated in d02, Figure S6: Total mean emission rates of isoprene, monoterpenes, and sesquiterpenes estimated in the BASE, NEW-VEG, and NEW-VEGEF cases 
during the target period, aggregated in d03, Figure S7: Horizontal distributions of mean surface MDA8O3 simulated in the BASE and NEW-VEGEF cases during the target period in d02. Differences between the two cases are also shown, Figure S8: Horizontal distributions of mean surface MDA8O3 simulated in the BASE and NEW-VEGEF cases during the target period in d03. Differences between the two cases are also shown, Figure S9: Horizontal distributions of mean surface SOA concentrations simulated in the BASE and NEW-VEGEF cases during the target period in d02. Differences between the two cases are also shown, Figure S10: Horizontal distributions of mean surface SOA concentrations simulated in the BASE and NEW-VEGEF cases during the target period in d03. Differences between the two cases are also shown, Figure S11: Horizontal distributions of differences of mean surface SOA concentrations originating from isoprene, monoterpenes, and sesquiterpenes simulated in the BASE and NEW-VEGEF cases from July 22nd to August 10th, 2013 in d02, d03, and d04, Figure S12: Horizontal distributions of mean surface SOA concentrations originating from isoprene, monoterpenes, and sesquiterpenes simulated in the NEW-VEGEF cases from July 22nd to August 10th, 2013 in d02, d03, and d04, Table S1: Default and newly developed EFs of isoprene, monoterpenes, and sesquiterpenes for major vegetation types. Average values and standard deviation are shown in $\mu \mathrm{g} / \mathrm{m}^{2} /$ hour.

Author Contributions: This study was conducted as part of the J-STREAM project. S.C. leads J-STREAM, and developed the new database and conducted air quality simulations. M.O. complied the EFs available in Japan. H.S. provided suggestions on air quality simulations and the EF database. K.Y. managed the inter-model comparisons and prepared the initial, boundary, and meteorological inputs to the air quality simulations. K.K. conducted air quality simulations. S.N.M. initiated and formulated pioneering studies related to developing BVOC emission inventories, including this study in Japan.

Acknowledgments: This research was supported by the Environment Research and Technology Development Fund (5-1601) of the Environmental Restoration and Conservation Agency. The new vegetation database was compiled by Ms. Miki Asai of the Asia Air Survey Co., Ltd., from the 6th and 7th Vegetation Surveys released by the Biodiversity Center of Japan, Ministry of Environment. Meteorological data were obtained from the Japan Meteorological Business Support Center. Observed ozone concentrations at APMSs were obtained from the environmental numerical database released by the National Institute for Environmental Studies (http:/ / www. nies.go.jp/igreen/). Data on observed $\mathrm{PM}_{2.5}$ components were obtained from the Ministry of the Environment, Government of Japan, available at: http:/ / www.env.go.jp/air/osen/pm/monitoring.html.

Conflicts of Interest: The authors declare no conflicts of interest.

\section{References}

1. Sartelet, K.N.; Couvidat, F.; Seigneur, C.; Roustan, Y. Impact of biogenic emissions on air quality over Europe and North America. Atmos. Environ. 2012, 53, 131-141. [CrossRef]

2. Wakamatsu, S.; Morikawa, T.; Ito, A. Air pollution trends in Japan between 1970 and 2012 and impact of urban air pollution countermeasures. Asian J. Atmos. Environ. 2013, 7, 177-190. [CrossRef]

3. Guenther, A.; Karl, T.; Harley, P.; Wiedinmyer, C.; Palmer, P.I.; Geron, C. Estimates of global terrestrial isoprene emissions using MEGAN (Model of Emissions of Gases and Aerosols from Nature). Atmos. Chem. Phys. 2006, 6, 3181-3210. [CrossRef]

4. Guenther, A.B.; Jiang, X.; Heald, C.L.; Sakulyanontvittaya, T.; Duhl, T.; Emmons, L.K.; Wang, X. The Model of Emissions of Gases and Aerosols from Nature version 2.1 (MEGAN2.1): An extended and updated framework for modeling biogenic emissions. Geosci. Model Dev. 2012, 5, 1471-1492. [CrossRef]

5. Sakulyanontvittaya, T.; Duhl, T.; Wiedinmyer, C.; Helmig, D.; Matsunaga, S.; Potosnak, M.; Milford, J.; Guenther, A. Monoterpene and sesquiterpene emission estimates for the United States. Environ. Sci. Technol. 2008, 42, 1623-1629. [CrossRef] [PubMed]

6. Kim, H.K.; Woo, J.H.; Park, R.S.; Song, C.H.; Kim, J.H.; Ban, S.J.; Park, J.H. Impacts of different plant functional types on ambient ozone predictions in the Seoul Metropolitan Areas (SMAs), Korea. Atmos. Chem. Phys. 2014, 14, 7461-7484. [CrossRef]

7. Kota, S.H.; Schade, G.; Estes, M.; Boyer, D.; Ying, Q. Evaluation of MEGAN predicted biogenic isoprene emissions at urban locations in Southeast Texas. Atmos. Environ. 2015, 110, 54-64. [CrossRef]

8. Sakulyanontvittaya, T.; Cho, S.; Aklilu, Y.A.; Morris, R.; Nopmongcol, U. An assessment of enhanced biogenic emissions influence on ozone formation in central Alberta, Canada. Air Qual. Atmos. Health 2016, 9, 117-127. [CrossRef]

9. Schurgers, G.; Arneth, A.; Hickler, T. Effect of climate-driven changes in species composition on regional emission capacities of biogenic compounds. J. Geophys. Res. Atmos. 2011, 116, D22. [CrossRef]

10. Wang, B.; Shugart, H.H.; Lerdau, M.T. An individual-based model of forest volatile organic compound emissions-UVAFME-VOC v1.0. Ecol. Model. 2017, 350, 69-78. [CrossRef] 
11. Chatani, S.; Matsunaga, S.N.; Nakatsuka, S. Estimate of biogenic VOC emissions in Japan and their effects on photochemical formation of ambient ozone and secondary organic aerosol. Atmos. Environ. 2015, 120, 38-50. [CrossRef]

12. Schicker, I.; Arias, D.A.; Seibert, P. Influences of updated land-use datasets on WRF simulations for two Austrian regions. Meteorol. Atmos. Phys. 2016, 128, 279-301. [CrossRef]

13. Cheng, F.Y.; Hsu, Y.C.; Lin, P.L.; Lin, T.H. Investigation of the effects of different land use and land cover patterns on mesoscale meteorological simulations in the Taiwan area. J. Appl. Meteorol. Climatol. 2013, 52, 570-587. [CrossRef]

14. Chatani, S.; Yamaji, K.; Sakurai, T.; Itahashi, S.; Shimadera, H.; Kitayama, K.; Hayami, H. Overview of model inter-comparison in Japan's Study for Reference Air Quality Modeling (J-STREAM). Atmosphere 2018, 9, 19. [CrossRef]

15. Skamarock, W.C.; Klemp, J.B.; Dudhia, J.; Gill, D.O.; Barker, D.M.; Duda, M.G.; Huang, X.Y.; Wang, W.; Powers, J.G. A Description of the Advanced Research WRF Version 3; NCAR/TN-475+STR; National Center for Atmospheric Research Boulder Co Mesoscale and Microscale Meteorology Div: Boulder, CO, USA, 2008.

16. Byun, D.; Schere, K.L. Review of the governing equations, computational algorithms, and other components of the models-3 Community Multiscale Air Quality (CMAQ) modeling system. Appl. Mech. Rev. 2006, 59, 51-77. [CrossRef]

17. Carter, W.P.L. Development of the SAPRC-07 chemical mechanism. Atmos. Environ. 2010, 44, 5324-5335. [CrossRef]

18. Carlton, A.G.; Bhave, P.V.; Napelenok, S.L.; Edney, E.D.; Sarwar, G.; Pinder, R.W.; Pouliot, G.A.; Houyoux, M. Model representation of secondary organic aerosol in CMAQv4.7. Environ. Sci. Technol. 2010, 44, 8553-8560. [CrossRef] [PubMed]

19. Griffin, R.J.; Cocker, D.R.; Flagan, R.C.; Seinfeld, J.H. Organic aerosol formation from the oxidation of biogenic hydrocarbons. J. Geophys. Res. Atmos. 1999, 104, 3555-3567. [CrossRef]

20. Bao, H.; Shrestha, K.L.; Kondo, A.; Kaga, A.; Inoue, Y. Modeling the influence of biogenic volatile organic compound emissions on ozone concentration during summer season in the Kinki region of Japan. Atmos. Environ. 2010, 44, 421-431. [CrossRef]

21. Okumura, M.; Tani, A.; Kominami, Y.; Takanashi, S.; Kosugi, Y.; Miyama, T.; Tohno, S. Isoprene emission characteristics of Quercus serrata in a deciduous broad-leaved forest. J. Agric. Meteorol. 2008, 64, 49-60. [CrossRef]

22. Tani, A.; Kawawata, Y. Isoprene emission from the major native Quercus spp. in Japan. Atmos. Environ. 2008, 42, 4540-4550. [CrossRef]

23. Matsunaga, S.N.; Muller, O.; Chatani, S.; Nakamura, M.; Nakaji, T.; Hiura, T. Seasonal variation of isoprene basal emission in mature Quercus crispula trees under experimental warming of roots and branches. Geochem. J. 2012, 46, 163-167. [CrossRef]

24. Ida, A.; Okajima, M.; Kishimoto, I.; Wu, W.; Sathiyamurthi, R.; Nakashima, Y.; Kato, S.; Chatani, S.; Yokouchi, Y.; Okumura, M.; et al. OH reactivity measurement and chemical analyses of BVOCs emitted from Sugi (Cryptomeria japonica). J. Jpn. Soc. Atmos. Environ. 2016, 51, 132-143.

25. Lin, C.Y.; Chang, T.C.; Chen, Y.H.; Chen, Y.J.; Cheng, S.S.; Chang, S.T. Monitoring the dynamic emission of biogenic volatile organic compounds from Cryptomeria japonica by enclosure measurement. Atmos. Environ. 2015, 122, 163-170. [CrossRef]

26. Matsunaga, S.N.; Mochizuki, T.; Ohno, T.; Endo, Y.; Kusumoto, D.; Tani, A. Monoterpene and sesquiterpene emissions from Sugi (Cryptomeria japonica) based on a branch enclosure measurements. Atmos. Pollut. Res. 2011, 2, 16-23. [CrossRef]

27. Matsunaga, S.N.; Niwa, S.; Mochizuki, T.; Tani, A.; Kusumoto, D.; Utsumi, Y.; Enoki, T.; Hiura, T. Seasonal variation in basal emission rates and composition of mono- and sesquiterpenes emitted from dominant conifers in Japan. Atmos. Environ. 2013, 69, 124-130. [CrossRef]

28. Okumura, M.; Ise, T.; Tani, A.; Miyama, T.; Kominami, Y.; Tohno, S. Effect of leaf temperature and light intensity on monoterpene emissions from Japanese Cedar (Cryptomeria japonica). Eco-Engineering 2013, 25, 117-121.

29. Mochizuki, T.; Endo, Y.; Matsunaga, S.; Chang, J.; Ge, Y.; Huang, C.A.; Tani, A. Factors affecting monoterpene emission from Chamaecyparis obtusa. Geochem. J. 2011, 45, E15-E22. [CrossRef] 
30. Okumura, M.; Tani, A.; Kosugi, Y.; Takanashi, S.; Miyama, T.; Kominami, Y.; Tohno, S. Diurnal and seasonal variations of monoterpene emissions from leaves of Chamaecyparis obtusa. Eco-Engineering 2008, 20, 89-95.

31. Lim, J.H.; Kim, J.C.; Kim, K.J.; Son, Y.S.; Sunwoo, Y.; Han, J.S. Seasonal variations of monoterpene emissions from Pinus densiflora in East Asia. Chemosphere 2008, 73, 470-478. [CrossRef] [PubMed]

32. Shibata, M.; Fujii, T.; Kishimoto, I.; Tsurumaru, H.; Sakamoto, Y.; Kajii, Y. Comprehensive evaluation of volatile organic compounds emitted from akamatsu (Pinus densiflora) by chemical analysis and $\mathrm{OH}$ reactivity measurements. ELCAS J. 2016, 1, 76-80.

33. Wei, D.; Fuentes, J.D.; Gerken, T.; Chamecki, M.; Trowbridge, A.M.; Stoy, P.C.; Katul, G.G.; Fisch, G.; Acevedo, O.; Manzi, A.; et al. Environmental and biological controls on seasonal patterns of isoprene above a rain forest in central Amazonia. Agric. For. Meteorol. 2018, 256-257, 391-406. [CrossRef]

34. Chatani, S.; Morikawa, T.; Nakatsuka, S.; Matsunaga, S.; Minoura, H. Development of a framework for a high-resolution, three-dimensional regional air quality simulation and its application to predicting future air quality over Japan. Atmos. Environ. 2011, 45, 1383-1393. [CrossRef]

35. Trieu, T.T.N.; Goto, D.; Yashiro, H.; Murata, R.; Sudo, K.; Tomita, H.; Satoh, M.; Nakajima, T. Evaluation of summertime surface ozone in Kanto area of Japan using a semi-regional model and observation. Atmos. Environ. 2017, 153, 163-181. [CrossRef]

36. Inoue, K.; Yasuda, R.; Yoshikado, H.; Higashino, H. Spatial distribution of summer-time surface ozone sensitivity to NOx and VOC emissions for the Kanto area Part 1: Estimation by numerical simulations with two kinds of (larger and smaller) biogenic emission estimates. J. Jpn. Soc. Atmos. Environ. 2010, 45, 183-194.

37. Kim, E.; Kim, B.U.; Kim, H.C.; Kim, S. The variability of ozone sensitivity to anthropogenic emissions with biogenic emissions modeled by MEGAN and BEIS3. Atmosphere 2017, 8, 187. [CrossRef]

38. Kato, S.; Shiobara, Y.; Uchiyama, K.; Miura, K.; Okochi, H.; Kobayashi, H.; Hatakeyama, S. Atmospheric CO, $\mathrm{O}_{3}$, and $\mathrm{SO}_{2}$ measurements at the summit of Mt. Fuji during the summer of 2013. Aerosol Air Qual. Res. 2016, 16, 2368-2377. [CrossRef]

39. Ghirardo, A.; Xie, J.F.; Zheng, X.H.; Wang, Y.S.; Grote, R.; Block, K.; Wildt, J.; Mentel, T.; Kiendler-Scharr, A.; Hallquist, M.; et al. Urban stress-induced biogenic VOC emissions and SOA-forming potentials in Beijing. Atmos. Chem. Phys. 2016, 16, 2901-2920. [CrossRef]

40. Brilli, F.; Barta, C.; Fortunati, A.; Lerdau, M.; Loreto, F.; Centritto, M. Response of isoprene emission and carbon metabolism to drought in white poplar (Populus alba) saplings. New Phytol. 2007, 175, $244-254$. [CrossRef] [PubMed]

41. Peñuelas, J.; Filella, I.; Seco, R.; Llusià, J. Increase in isoprene and monoterpene emissions after re-watering of droughted Quercus ilex seedlings. Biol. Plant. 2009, 53, 351-354. [CrossRef]

42. Saunier, A.; Ormeno, E.; Wortham, H.; Temime-Roussel, B.; Lecareux, C.; Boissard, C.; Fernandez, C. Chronic drought decreases anabolic and catabolic BVOC emissions of Quercus pubescens in a Mediterranean Forest. Front. Plant Sci. 2017, 8, 71. [CrossRef] [PubMed]

43. Xie, Y.; Paulot, F.; Carter, W.P.L.; Nolte, C.G.; Luecken, D.J.; Hutzell, W.T.; Wennberg, P.O.; Cohen, R.C.; Pinder, R.W. Understanding the impact of recent advances in isoprene photooxidation on simulations of regional air quality. Atmos. Chem. Phys. 2013, 13, 8439-8455. [CrossRef]

44. Van Eijck, A.; Opatz, T.; Taraborrelli, D.; Sander, R.; Hoffmann, T. New tracer compounds for secondary organic aerosol formation from beta-caryophyllene oxidation. Atmos. Environ. 2013, 80, 122-130. [CrossRef]

45. Saunders, S.M.; Jenkin, M.E.; Derwent, R.G.; Pilling, M.J. Protocol for the development of the Master Chemical Mechanism, MCM v3 (Part A): Tropospheric degradation of non-aromatic volatile organic compounds. Atmos. Chem. Phys. 2003, 3, 161-180. [CrossRef]

46. Matsui, H.; Koike, M.; Takegawa, N.; Kondo, Y.; Griffin, R.J.; Miyazaki, Y.; Yokouchi, Y.; Ohara, T. Secondary organic aerosol formation in urban air: Temporal variations and possible contributions from unidentified hydrocarbons. J. Geophys. Res. Atmos. 2009, 114. [CrossRef]

47. Morino, Y.; Takahashi, K.; Fushimi, A.; Tanabe, K.; Ohara, T.; Hasegawa, S.; Uchida, M.; Takami, A.; Yokouchi, Y.; Kobayashi, S. Contrasting diurnal variations in fossil and nonfossil secondary organic aerosol in urban outflow, Japan. Environ. Sci. Technol. 2010, 44, 8581-8586. [CrossRef] [PubMed]

48. Morino, Y.; Nagashima, T.; Sugata, S.; Sato, K.; Tanabe, K.; Noguchi, T.; Takami, A.; Tanimoto, H.; Ohara, T. Verification of chemical transport models for $\mathrm{PM}_{2.5}$ chemical composition using simultaneous measurement data over Japan. Aerosol Air Qual. Res. 2015, 15, 2009-2023. [CrossRef] 
49. Alves, C.; Vicente, A.; Pio, C.; Kiss, G.; Hoffer, A.; Decesari, S.; Prevot, A.S.H.; Minguillon, M.C.; Querol, X.; Hillamo, R.; et al. Organic compounds in aerosols from selected European sites-Biogenic versus anthropogenic sources. Atmos. Environ. 2012, 59, 243-255. [CrossRef]

50. Matsunaga, S.N.; Shimada, K.; Masuda, T.; Hoshi, J.; Sato, S.; Nagashima, H.; Ueno, H. Emission of Biogenic Volatile Organic Compounds from Trees along Streets and in Urban Parks in Tokyo, Japan. Asian J. Atmos. Environ. 2017, 11, 29-32. [CrossRef]

51. Wang, B.; Shuman, J.; Shugart, H.H.; Lerdau, M.T. Biodiversity matters in feedbacks between climate change and air quality: A study using an individual-based model. Ecol. Appl. 2018. [CrossRef] [PubMed]

2018 by the authors. Licensee MDPI, Basel, Switzerland. This article is an open access article distributed under the terms and conditions of the Creative Commons Attribution (CC BY) license (http://creativecommons.org/licenses/by/4.0/). 